\title{
A Critical Question: Can we Trust Smartphone Survey Data?
}

\author{
Murat Tuncer \\ Correspondence: Murat Tuncer, Frrat University, Education Faculty, Turkey. \\ Received: April 7, 2017 \\ Accepted: April 18, 2017 \\ Online Published: April 24, 2017 \\ doi:10.11114/jets.v5i6.2337 \\ URL: https://doi.org/10.11114/jets.v5i6.2337
}

\begin{abstract}
The main aim of this study is to determine whether a significant difference exits among data collection with printed materials and with smart phones. The research was conducted with 282 teacher candidates who take pedagogical formation training. Three data collection tools were used throughout the study. As the results of the current research, no significant differences were obtained among attitude scores towards teaching profession with regard to common effect of application method and faculty variables. However, significant differences in participant opinions were determined among different application methods (smartphone and printed) of Metacognitive Thinking Skills and Information Literacy Scales. In addition, no significant difference was found among opinions towards Metacognitive Thinking Skills and Information Literacy Scales with regard to common effect of application method and faculty variables. Based on these research findings, it is not recommended to distribute survey items containing technical information or some complex expressions via smartphones. Relations among the questionnaire content and the department of education confirm this situation.
\end{abstract}

Keywords: smartphone, Online survey, Information Literacy, Metacognition Skills, Attitude towards teaching profession

\section{Introduction}

Technology is able to change human behavior through innovations it presents. Without going through scientific inquiry, it is not possible for us to know what changing human behaviors really are and how they can be explained. Change at such rapid rate and sectorial differences, is causing difficulties in explaining and managing them. Throughout this study, this situation which appears in many sectors is handled through its educational aspect.

Survey is among the research methods that researchers apply to in social sciences. With the effect of quantitative paradigm, researchers have been referring to a number of ways within survey method to maintain validity and reliability of data collection tools and to reach large samples. Advances in technology have opened the gate to online applications of data collection tools to achieve these goals. Over time, this opportunity has become quite widespread, but possible limitations of this new data collection method have not been an issue thoroughly considered.

Current situation of technology based learning is an issue of interest for a number of researchers. Remarkable research studies can be seen in literature on human behaviors and impact of technology. For example, it was observed that the internet has begun to be seen as the primary source for learning (Tuncer, Y1lmaz and Tan, 2011; Tuncer and Kaysi, 2011) and also with the prevailing internet technology, disposition of getting information through books and libraries is gradually weakening whereas we approach to a point where learning in a virtual environment, called screen reading, is being preferred (Tuncer and Bahadir, 2014). But according to a number of researches (More, Guy and Elobaid, 2007; Alshaali and Varshney, 2005; Annand, 2008; Weeks, 2002; Spencer, 2006; Vernon, 2006) learners prefer printed materials instead of screen reading. Besides, according to Stoop, Kreutzer and Kircz (2013) e-readers display such behaviors as not being able to take notes with ease, slow reading, postponing examinations and printing out e-books. Johnson (2000) explained the reason of preferring printed material for reading as successful readers get bored of simple texts and weak readers abandon reading texts which are not fluent.

Reading is important for learning, but reading comprehension is important as well. Çelik (2006), states that reading is composed of various functions of eye, speech organs and cognition such as perceiving what is seen, comprehending what is perceived, stating what is comprehended and constructing in mind. Studies on reading effectiveness in learning differ in terms of organ functions. For instance, reading is slower in oral reading due to attention and time loss. Meantime, semantic loss can also occur (MNE (Ministry National Education), 2011). Compared to silent reading, oral reading is more beneficial in learning short texts because it addresses both eyes and ears (Aytaş, 2005). During silent 
reading, words and sentences are followed by eye without vocalizing. As soon as the eye perceives, it transmits text to memory to be processed. In this reading type (silent reading), vocal cords, sound waves, tongue and ear stay out of the reading process (Güneş, 2007). In silent reading, connection of vision-comprehension is needed. It is seen as a faster type of reading compared to oral reading and is considered important due to acuteness it provides (Müftüoğlu and Koç, 1998: 64). According to Çelik (2006), the brain comprehends what is read faster for what eyes see keeps it busy enough and it cannot find any other endeavor.

Joy Bolter pointed computers as the fourth large document medium after papyrus plant, which ancient Egyptians made sails, fabric, straw and writing paper out of its stem, medieval books and printed books (O'Hara and Sellen, 1997). According to Dyson (2004) besides rapid development of web technology, also spreading word processers used to create documents increased number of screen-read documents. Executing most of the studies in the field of education through computers, projecting documents such as e-books, articles and online journals onto the screens using computer-type devices show that screen-reading has become a necessity at schools as well. According to Maden (2012), screen-reading is a type of reading which an individual encounter frequently but uses unwittingly. Anameriç and Rukanc1 (2003) stated that owning a printed book is a privilege, touching it and sensing its smell arouse different feelings. On the contrary, e-books have some conveniences such as lower prices compared with printed books, easier portability and dissemination possibility over the internet. Yıldırım and others (2011) suggest that screen-reading may be advantageous to reading from printed materials due to adjustable screen size and resolution. Reading would be comfortable if screen page is A4 or A5 size, emphasized Mallet (2010). Furthermore, while large text screen is necessary to be able to see the whole page, it is not found favorable as it can create a physical weight.

May these positive and negative findings towards on-screen text reading appear during data collection by online surveys which researchers frequently apply? Researchers may prefer online data collection for a number of reasons such as reaching different and larger samples, more economical data collection and avoiding unanswered questions (where answering a question is obligatory). As a matter of fact, in the era of the internet, Strachota, Schmidt and Conceicao (2005) see online surveys as an efficient way of data collection. Schmidt, Strachota and Conceição (2006) and also Rose and Bogue (2006) see online questionnaire distribution advantageous from a number of point of views such as saving time, reducing data entry error, increasing product response rate and reducing cost. The disadvantages of the online survey in this research include the need for specific computer skills such as use of pop-up menus and scrolling, the need for user-friendly software to maintain careful reading of instructions and paying attention to detail. Gunn (2002) believes that web page design skills and computer programming expertise play an important role in web-based questionnaire design, unlike other types of questionnaires. Timmerman (2002) emphasizes that online questionnaires should be investigated as to whether the target audience is appropriate for the research topic. In a study they conducted, Rosa, Bressan and Toledo (2012) concluded that online questionnaires might be used, but they had certain limitations in terms of tools. According to Rose and Bogue (2006), the most important issue to be considered when evaluating on-line questionnaires is the opportunity to access the internet and quality of the access. Fleming and Bowden (2009) pointed out that sampling biases in web-based surveys may cause problems in terms of research findings. Similarly, Bushanan and Hvizdak (2009) pointed the dimensions such as security, privacy, sampling, consent, design and spamming in web-based surveys. Due to the current technology, the management of online surveys has resulted in increased time efficiency by both distributing and retrieving survey results online. However, this does not change the fact that the main criterion of the measurement is to reach valid data. Despite the fact that, online data collection is preferred in many studies, researchers have hardly ever questioned this mandatory criterion. There are a number of conducted studies closely related to the research topic (Fleming and Bowden, 2009; Nulty, 2008; Strachota, Schmidt and Conceicao, 2005; Schmidt, Strachota and Conceição, 2006; Rose and Bogue, 2006; Morris, Woo and Cho, 2003; Szolnoki and Hoffman, 2013; Wiersme, 2013). However, findings may be related to data collection tools utilized. For this reason, findings obtained in the study were evaluated according to primarily to the method utilized. Secondly, multiple data collection tools were used in the sense that the findings could be derived from data collection tools.

\section{Method}

The design of this study can said to be a survey model. As Karasar (2009) puts it, it is aimed to describe past or present situations in the survey model. The main aim of this study is to determine whether a significant difference exits among data collection with printed materials and with smart phones. Studies on comparison of printed and internet based applications (smartphones) of data collection tools are seen in the related literature. However, no studies which are free from scale effect and are on comparison of printed and smart phone survey scores have been encountered. With the use of smart phones more functionally in every environment, it can be stated that smart phones will start to replace computers for accessing the internet. Therefore, it may be considered that the current research topic contains a specific problem situation.

The research was conducted with 282 teacher candidates who take pedagogical formation training at Frrat University 
Faculty of Education. 29 teacher candidates who did not accept to participate and 33 candidates who did not own smartphones were excluded from the actual sample size of 344 people. Thus, it was ensured that the research was conducted on a voluntary group having smart phone skills. The distribution of teacher candidates in respect to their faculties is as; Sport Sciences $(\mathrm{N}=59)$, Humanities and Social Sciences $(\mathrm{N}=62)$, Economics and Administrative Sciences $(\mathrm{N}=60)$, Science $(\mathrm{N}=50)$ and Theology $(\mathrm{N}=51)$. Virtual survey group consists of 155 while printed survey group consists of 127 teacher candidates. Groups were assigned randomly.

Independent samples $t$ test, coefficient of variation, effect size and two-way analysis of variance were used to evaluate research data. A coefficient of variation smaller than 20 is interpreted as a homogenous distribution while a value between 20 and 25 is interpreted as a normal distribution and a value larger than 25 is interpreted as a heterogeneous distribution (Karaca, 2008: 264). Intervals stated by Green and Salkind (1997; cited by Büyüköztürk, Çokluk and Köklü, 2012:189) and Cohen's (1988) effect sizes ( $\geq 0.5$ : strong, $\geq 0.3$ : medium and $\geq .01$ weak) were taken into consideration together for the interpretation of effect size.

\section{Data Collection Tools}

Three data collection tools were used throughout the study. The Information Literacy Self-Efficacy Scale (ILSE) was developed by Kurbanoğlu, Akkoyunlu and Umay (2006) and adapted to Turkish by Tuncer (2013). The tool is a 7-point Likert type scale which enables "Almost Every Time True", "Generally True", "Often True", "Sometimes True", "Rarely True", "Generally not True", "Almost Never True" responses. Scoring was done as: 7 for "Almost Every Time True", 6 for "Generally True", 5 for "Often True", 4 for "Sometimes True", 3 for "Rarely True", 2 for "Generally not True" and 1 for "Almost Never True". The second data collection tool of the study, Metacognitive Thinking Skills Scale (MCTS) was developed by Tuncer and Kaysi (2013). This scale consists of 18 items under 4 dimensions. These dimensions are: thinking skills, reflective thinking skills for problem solving, decision making skills and alternative assessment skills. Four dimensions of the scale explain $56.579 \%$ of total variance. Five-point Likert type scales are scored as 5 for "Completely Agree", 4 for "Agree", 3 for "Undecided", 2 for "Disagree" and 1 for "Completely Disagree". The third data collection tool of the study is Attitude towards Teaching Profession (ATTP) Scale which has 35 items, was developed by Çetin (2006). Each student who responded, scored according to a five-point Likert type scale: 5 for "Strongly Agree", 4 for "Agree", 3 for "Undecided", 2 for "Disagree" and 1 for "Never Agree". On the other hand, each student scored the items with a negative stem as: 1 for "Strongly Agree", 2 for "Agree", 3 for "Undecided", 4 for "Disagree" and 5 for "Never Agree".

Information Literacy Scale consists of 4 sub-dimensions (library literacy, information literacy, bibliography literacy and scientific research literacy). While MCST Scale consists of 4 sub-dimensions (thinking, problem solving, decision making and alternative evaluation), Attitudes towards Teaching Profession Scale (ATTP) consists of 3 sub-dimensions (love, value, harmony). Reliability coefficients were found as .874 for MCST Scale, .935 for Information Literacy Scale and .914 for Attitudes towards Teaching Profession Scale.

\section{Findings}

Comparisons of findings towards scales filled in online and printed, in terms of sub-dimensions, distribution of the answers and effects of the application method on the responses, are presented in Table 1.

It was determined that opinions regarding Attitude towards Teaching Profession Scale did not differ significantly $(\mathrm{p}>.05)$ according to the application method. Besides, coefficient of variability showed homogenous distributions of the answers in terms of love, value and harmony sub-dimensions and the whole scale. Significant differences $(\mathrm{p}<.05)$ among all sub-dimensions of Metacognitive Thinking and Information Literacy scales were also observed according to the application method. When the scale dimensions with significant differences among the opinions were evaluated in terms of effect size, it was determined that the application method was strongly effective on thinking and problem solving sub-dimensions and on the whole scale, but moderately effective on alternative assessment sub-dimension of MCST scale and also strongly effective on all sub-dimensions and the whole of Library Literacy scale. 
Table 1. Analyses on comparison of the responses according to the application method and distribution of the answers

\begin{tabular}{|c|c|c|c|c|c|c|c|c|c|}
\hline Scale & Dimension & Application & $\mathrm{X}$ & SD & $\mathrm{V}$ & $\mathrm{t}$ & $\mathrm{p}$ & Distribution & Ef. Size \\
\hline \multirow{8}{*}{ ATTPS } & \multirow{2}{*}{ Love } & Smartphone & 3,90 & ,71 & 18,20 & \multirow{2}{*}{$-1,230$} & \multirow{2}{*}{,220 } & homogeneous & \\
\hline & & Printed & 4,00 & 72 & 18,00 & & & homogeneous & \\
\hline & \multirow{2}{*}{ Value } & Smartphone & 4,56 & ,48 & 10,52 & \multirow{2}{*}{, 736} & \multirow{2}{*}{,998 } & homogeneous & \\
\hline & & Printed & 4,56 & ,47 & 10,30 & & & homogeneous & \\
\hline & \multirow{2}{*}{ Harmony } & Smartphone & 3,65 &, 47 & 12,87 & \multirow{2}{*}{1,923} & \multirow{2}{*}{055} & homogeneous & \\
\hline & & Printed & 3,52 &, 70 & 19,88 & & & homogeneous & \\
\hline & \multirow{2}{*}{ Whole } & Smartphone & 4,01 &, 55 & 13,71 & \multirow{2}{*}{$-1,733$} & \multirow{2}{*}{,464 } & homogeneous & \\
\hline & & Printed & 4,06 &, 57 & 14,03 & & & homogeneous & \\
\hline \multirow{10}{*}{ MCTS } & \multirow{2}{*}{ Thinking } & Smartphone & 4,27 &, 40 & 9,37 & \multirow{2}{*}{9,031} & \multirow{2}{*}{, $000 *$} & homogeneous & \multirow{2}{*}{,231 } \\
\hline & & Printed & 3,68 & ,68 & 18,48 & & & homogeneous & \\
\hline & \multirow{2}{*}{ Problem Solv. } & Smartphone & 3,98 &, 52 & 13,07 & \multirow{2}{*}{3,869} & \multirow{2}{*}{, $000 *$} & homogeneous & \multirow{2}{*}{,066 } \\
\hline & & Printed & 3,68 &, 77 & 20,92 & & & Normal Dist. & \\
\hline & \multirow{2}{*}{$\begin{array}{l}\text { Decision } \\
\text { Making }\end{array}$} & Smartphone & 4,18 &, 54 & 12,92 & \multirow{2}{*}{3,363} & \multirow{2}{*}{, $001^{*}$} & homogeneous & \multirow{2}{*}{,096 } \\
\hline & & Printed & 3,92 & ,76 & 19,39 & & & homogeneous & \\
\hline & \multirow{2}{*}{$\begin{array}{l}\text { Alternative } \\
\text { Evaluation }\end{array}$} & Smartphone & 3,95 &, 52 & 13,16 & \multirow{2}{*}{2,969} & \multirow{2}{*}{, $003 *$} & homogeneous & \\
\hline & & Printed & 3,71 &, 80 & 21,56 & & & Normal Dist. & ,030 \\
\hline & Whole & Smartphone & 4,11 & ,38 & 9,25 & 6260 & $000 *$ & homogeneous & 144 \\
\hline & WHoic & Printed & 3,74 & ,60 & 16,04 & & & homogeneous & \\
\hline & & Smartphone & 4,66 & 1,36 & 29,18 & & & heterogeneous & \\
\hline & Library & Printed & 3,83 & 1,62 & 42,30 & &, $000^{*}$ & heterogeneous & ,086 \\
\hline & Information & Smartphone & 5,33 & ,95 & 17,82 & & $006 *$ & homogeneous & 04 \\
\hline & Information & Printed & 5,00 & 1,02 & 20,40 & & - & Normal Dist. & ,042 \\
\hline UL SF & Bibliooranhy & Smartphone & 4,66 & 1,44 & 30,90 & & $0 \cap 0 *$ & heterogeneous & \\
\hline ILSE & Bibliography & Printed & 3,93 & 1,46 & 37,15 & &, $000^{2}$ & heterogeneous &, $0 / 9$ \\
\hline & search & Smartphone & 5,04 & 1,14 & 22,62 & & $03 *$ & Normal Dist. & \\
\hline & Sc1.Research & Printed & 4,64 & 1,12 & 24,14 & &, $003^{*}$ & Normal Dist. & \\
\hline & & Smartphone & 4,98 & 1,00 & 20,08 & & 000 & Normal Dist. & \\
\hline & & Printed & 4,45 & 1,01 & 22,70 & & - & Normal Dist. & \\
\hline
\end{tabular}

During the research, two-way analysis of variance was performed with respect to the application method and faculty. The results of two-way analysis of variance regarding the Attitude Toward Teaching Profession Scale are given in Table 2.

Table 2. ANOVA analysis of Attitude Toward Teaching Profession Scale with respect to the application method and faculty

\begin{tabular}{llllll}
\hline Source & Sum of Squares & df & Mean Squares & F & p \\
\hline Application &, 464 & 1 &, 464 & 1,476 &, 226 \\
Faculty & 2,125 & 4 &, 531 & 1,689 &, 153 \\
Application x Faculty & 1,319 & 4 &, 330 & 1,409 &, 382 \\
Error & 21,676 & 272 &, 080 & & \\
\hline Total & 2917,768 & 282 & & & \\
\hline
\end{tabular}

According to the table, no significant difference $(\mathrm{p}>.05)$ was found among scores of attitudes towards teaching profession in terms of common effect of application method and faculty. A line graph displaying this dimension is given in Figure 1.

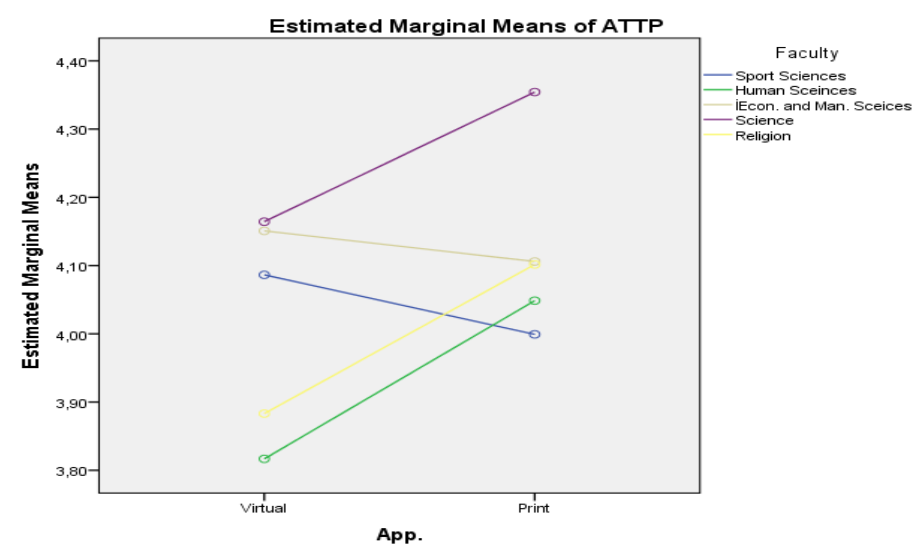

Figure 1. Method and Faculty Axial Line Graph of Attitudes towards Teaching Profession Scale

When an evaluation is made in terms of average scores of the application method, printed survey averages were found 
lower than online survey averages for the faculties of Sport Sciences, Economics and Administrative Sciences. Averages of printed surveys were found higher for the faculties of Science, Theology and Humanities and Social Sciences. Average opinion scores for ATTP Scale with regard to application type and faculty are given in Table 3.

In the virtual application of the Attitudes towards Teaching Profession Scale, the highest average score was found for Science Faculty $(X=4.16 \pm .40)$ while the lowest average score was found for Humanities and Social Sciences Faculty $(\mathrm{X}=3.81 \pm .52)$. Similarly, regarding printed application, the highest average score $(\mathrm{X}=4.35 \pm .33)$ was found for Science Faculty and the lowest average score was found for Humanities and Social Sciences Faculty $(\mathrm{X}=3.95 \pm .58)$. When a general evaluation is made, it was seen that virtual survey application $(X=4.01 \pm .55)$ produced a lower average than printed survey application $(X=4.06 \pm .57)$.

Table 3. Descriptive Statistics Based on Application Method and Faculty (ATTP Scale)

\begin{tabular}{llll}
\hline & Faculty & $\bar{X}$ & Std. Deviation \\
\hline \multirow{5}{*}{ Smartphonen } & Sport Sciences & 4,08 &, 60 \\
\cline { 2 - 4 } & Human Sciences & 3,81 &, 52 \\
\cline { 2 - 4 } & Econ. and Manag. & 4,15 &, 60 \\
\cline { 2 - 4 } & Science & 4,16 &, 40 \\
\cline { 2 - 4 } & Religion & 3,88 &, 51 \\
\cline { 2 - 4 } & Total & 4,01 &, 55 \\
\hline \multirow{5}{*}{ Printed } & Sport Sciences & 4,04 &, 64 \\
\cline { 2 - 4 } & Human Sciences & 3,95 &, 58 \\
\cline { 2 - 4 } & Econ. and Manag. & 4,10 &, 50 \\
\cline { 2 - 4 } & Science & 4,35 &, 33 \\
\cline { 2 - 4 } & Religion & 4,10 &, 55 \\
\cline { 2 - 4 } & Total & 4,06 &, 57 \\
\cline { 2 - 4 } & Sport Sciences & 4,04 &, 64 \\
\cline { 2 - 4 } & Human Sciences & 3,95 &, 56 \\
\cline { 2 - 4 } & Econ. and Manag. & 4,12 &, 54 \\
\cline { 2 - 4 } & Science & 4,19 &, 39 \\
\cline { 2 - 4 } & Religion & 3,93 &, 52 \\
\cline { 2 - 3 } & Total & 4,04 &, 56 \\
\hline
\end{tabular}

In the virtual application of the Attitudes towards Teaching Profession Scale, the highest average score was found for Science Faculty $(X=4.16 \pm .40)$ while the lowest average score was found for Humanities and Social Sciences Faculty $(\mathrm{X}=3.81 \pm .52)$. Similarly, regarding printed application, the highest average score $(\mathrm{X}=4.35 \pm .33)$ was found for Science Faculty and the lowest average score was found for Humanities and Social Sciences Faculty $(\mathrm{X}=3.95 \pm .58)$. When a general evaluation is made, it was seen that virtual survey application $(X=4.01 \pm .55)$ produced a lower average than printed survey application $(\mathrm{X}=4.06 \pm .57)$.

Results of two-way analysis of variance of the opinions towards Metacognitive Thinking Skills Scale, the second data gathering tool of the research, are summarized in Table 4 in terms of method and faculty variables.

Table 4. ANOVA analysis of the Opinions towards MCTS Scale with regard to Application Method and Faculty

\begin{tabular}{llllll}
\hline Source & Sum of Squares & df & Mean Squares & F & p \\
\hline Application & 6,084 & 1 & 6,084 & 24,724 &, 000 \\
Faculty &, 801 & 4 &, 200 &, 813 &, 518 \\
Application x Faculty &, 552 & 4 &, 138 &, 561 &, 691 \\
Error & 67,180 & 273 &, 246 & & \\
\hline Total & 4483,659 & 283 & & & \\
\hline
\end{tabular}

According to the table, a significant difference $(\mathrm{F}(1.273)=24.724, \mathrm{p}<.05)$ among scores of Metacognitive Thinking Skills Scale with regard to application method (virtual and printed) was determined. However, no significant difference $(\mathrm{F}(1.273)=24.724, \mathrm{p}>.05)$ was determined among scores of Metacognitive Thinking Skills Scale with regard to common effect of application method and faculty. Line graph regarding this situation is like at Figure 2. 


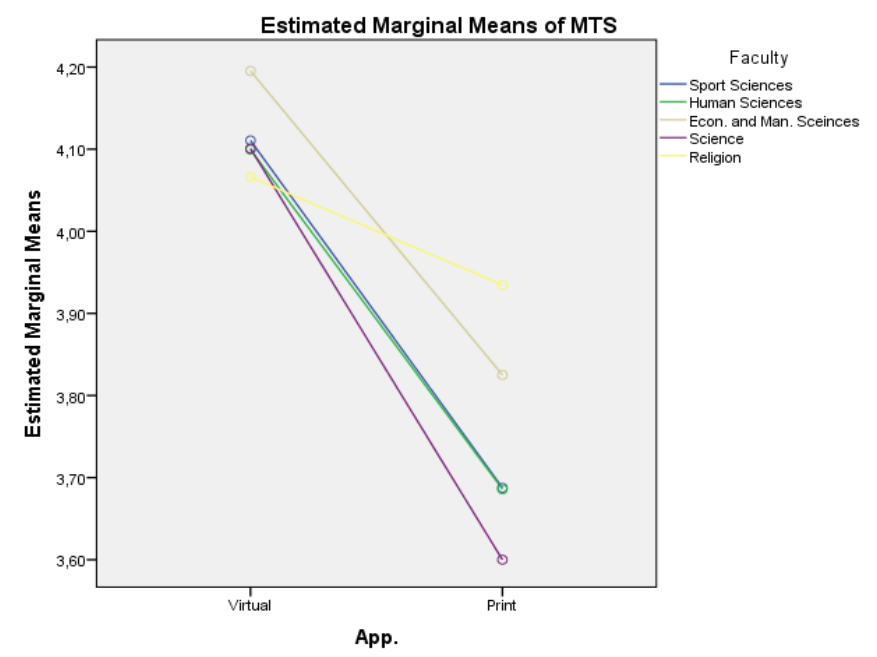

Figure 2. Line Graph of MCTS Scale Based on Method and Faculty

When an evaluation is performed among average scores of application methods, it is seen that virtual scores are higher in all faculties. Average opinion scores for Metacognitive Thinking Skills Scale with regard to application type and faculty are given in Table 5 .

Table 5. Descriptive Statistics based on Application Method and Faculty (MCTS Scale)

\begin{tabular}{llll}
\hline & Faculty & $\bar{X}$ & Std. Deviation \\
\hline \multirow{5}{*}{ Smartphone } & Sport Sciences & 4,11 &, 29 \\
\cline { 2 - 4 } & Human Sciences & 4,10 &, 36 \\
\cline { 2 - 4 } & Econ. and Manag. & 4,20 &, 46 \\
\cline { 2 - 4 } & Science & 4,10 &, 29 \\
\cline { 2 - 4 } & Religion & 4,07 &, 51 \\
\cline { 2 - 4 } & Total & 4,11 &, 38 \\
\hline \multirow{5}{*}{ Printed } & Sport Sciences & 3,69 &, 62 \\
\cline { 2 - 4 } & Human Sciences & 3,69 &, 61 \\
\cline { 2 - 4 } & Econ. and Manag. & 3,83 &, 63 \\
\cline { 2 - 4 } & Science & 3,60 &, 62 \\
\cline { 2 - 4 } Total & Religion & 3,93 &, 34 \\
\cline { 2 - 4 } & Total & 3,74 &, 60 \\
\cline { 2 - 4 } & Sport Sciences & 3,91 &, 52 \\
\cline { 2 - 4 } & Human Sciences & 3,86 &, 56 \\
\cline { 2 - 4 } & Econ. and Manag. & 3,97 &, 59 \\
\cline { 2 - 4 } & Science & 4,02 &, 39 \\
\cline { 2 - 3 } & Religion & 4,04 &, 47 \\
\cline { 2 - 3 } & Total & 3,95 &, 53 \\
\hline
\end{tabular}

Regarding the virtual application of the Metacognitive Thinking Skills Scale, the highest average point was found for Economical and Administrative Sciences Faculty $(X=4.20 \pm .46)$ and the lowest for Theology Faculty $(X=4.07 \pm .51)$ $\pm .34)$ while regarding printed application of the scale, the highest average point was found for Theology Faculty $(\mathrm{X}=$ $3.93 \pm .34)$ and the lowest average point was found for Science Faculty $(\mathrm{X}=3.60 \pm .62)$. When a general evaluation was made, it was determined that the average of the virtual survey application $(X=4.11 \pm .38)$ was higher than the average of the printed survey $(\mathrm{X}=3.74 \pm .60)$.

The third data collection tool of the research is the Information Literacy Scale. Results of the two-way analysis of variance for this data collection tool in terms of method and faculty variables are summarized in Table 6.

Table 6. ANOVA analysis of opinions towards Information Literacy Scale regarding application method and faculty

\begin{tabular}{llllll}
\hline Source & Sum of Squares & df & Mean Squares & F & $\mathrm{p}$ \\
\hline Application & 18,438 & 1 & 18,438 & 18,429 &, 000 \\
Faculty & 6,416 & 4 & 1,604 & 1,603 &, 174 \\
Application x Faculty & 7,802 & 4 & 1,950 & 1,949 &, 103 \\
Error & 275,144 & 275 & 1,001 & & \\
\hline Total & 6735,851 & 285 & & & \\
\hline
\end{tabular}

According to the table, a significant difference in participant opinions towards Information Literacy Scale was determined $(\mathrm{F}(1.275)=18.429, \mathrm{p}<.05)$ among the virtual and printed applications. However, no significant difference $(\mathrm{F}(1.275)=1.949, \mathrm{p}>.05)$ was found among the opinions towards Information Literacy Scale with regard to common 
effect of faculty and application method. The line graph displaying this situation is given in Figure 3.

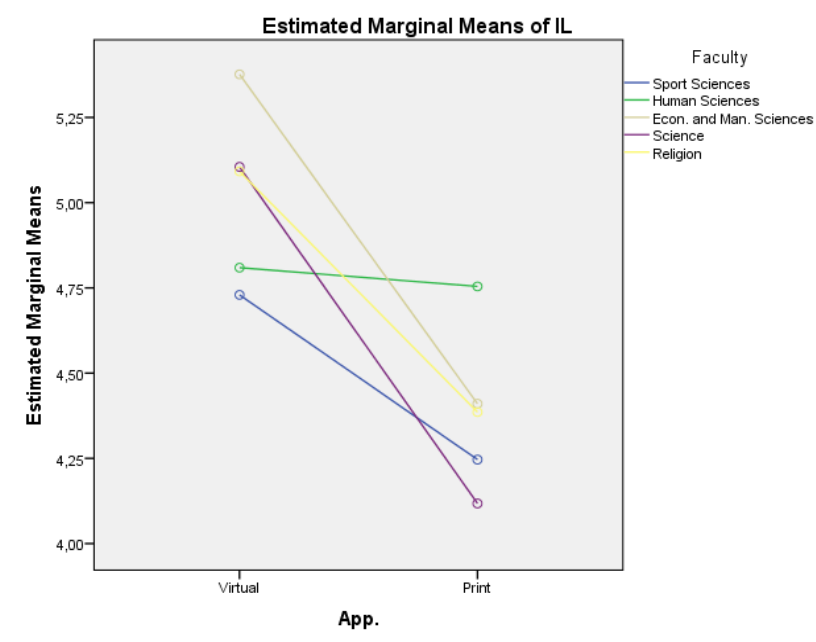

Figure 3. Line Graph of Information Literacy Scale Based on Method and Faculty

When an evaluation is made in terms of the average scores according to the method applied, it is seen that the average virtual scores are higher in all the faculties. It is also seen that the closest points among the virtual and printed surveys of the Information Literacy Scale are for Humanities and Social Sciences Faculty. Regarding the Information Literacy Scale, average points of application method with respect to faculties are given in Table 7.

In the virtual application of the Information Literacy Scale, the highest average point was found for Humanities and Social Sciences Faculty $(X=5.38 \pm .89)$ and the lowest average point was found for Sports Sciences Faculty $(X=4.73$ $\pm 1.16)$ moreover, regarding printed application of the scale, the highest average point was found for Humanities and Social Sciences Faculty $(4.75 \pm 0.93)$ and the lowest average point was found for Science Faculty $(X=4.12 \pm 1.05)$. When a general evaluation was made, it was determined that the average of the virtual survey application $(\mathrm{X}=4.99 \pm$ 1.01) was higher than the average of the printed application $(X=4.46 \pm 1.01)$.

Table 7. Descriptive Statistics Based on Application Method and Faculty (IL Scale)

\begin{tabular}{llll}
\hline & Faculty & $\bar{X}$ & Std. Deviation \\
\hline \multirow{5}{*}{ Smartphone } & Sport Sciences & 4,73 & 1,16 \\
\cline { 2 - 4 } & Human Sciences & 4,81 &, 98 \\
\cline { 2 - 4 } & Econ. and Manag. & 5,38 &, 89 \\
\cline { 2 - 4 } & Science & 5,11 & 1,02 \\
\cline { 2 - 4 } & Religion & 5,09 &, 80 \\
\cline { 2 - 4 } & Total & 4,99 & 1,01 \\
\hline \multirow{5}{*}{ Printed } & Sport Sciences & 4,25 & 1,00 \\
\cline { 2 - 4 } & Human Sciences & 4,75 &, 93 \\
\cline { 2 - 4 } & Econ. and Manag. & 4,41 & 1,10 \\
\cline { 2 - 4 } & Science & 4,12 & 1,05 \\
\cline { 2 - 4 } & Religion & 4,39 &, 94 \\
\cline { 2 - 4 } Total & Total & 4,46 & 1,01 \\
\cline { 2 - 4 } & Sport Sciences & 4,50 & 1,11 \\
\cline { 2 - 4 } & Human Sciences & 4,78 &, 94 \\
\cline { 2 - 4 } & Econ. and Manag. & 4,79 & 1,12 \\
\cline { 2 - 4 } & Science & 4,96 & 1,07 \\
\cline { 2 - 3 } & Religion & 4,94 &, 87 \\
\cline { 2 - 3 } & Total & 4,75 & 1,04 \\
\hline
\end{tabular}

In the virtual application of the Information Literacy Scale, the highest average point was found for Humanities and Social Sciences Faculty $(X=5.38 \pm .89)$ and the lowest average point was found for Sports Sciences Faculty $(X=4.73$ $\pm 1.16)$ moreover, regarding printed application of the scale, the highest average point was found for Humanities and Social Sciences Faculty $(4.75 \pm 0.93)$ and the lowest average point was found for Science Faculty $(X=4.12 \pm 1.05)$. When a general evaluation was made, it was determined that the average of the virtual survey application $(\mathrm{X}=4.99 \pm$ 1.01) was higher than the average of the printed application $(X=4.46 \pm 1.01)$.

Within the content of the study, reliabilities of the printed and virtual scales were also investigated as it is important to test the findings in terms of reliability. Findings on reliability analysis are given in Table 8. 
Table 8. Reliability Coefficients of the Scales in terms of Applied Methods

\begin{tabular}{llll}
\hline Application & MCTS & ILSE & ATTPS \\
\hline Smartphone &, 807 &, 938 &, 907 \\
\hline Printed &, 883 &, 924 &, 922
\end{tabular}

As it is seen in the table, reliability coefficients of printed applications of Metacognitive Thinking and Attitudes towards Teaching Profession scales, and virtual application of Information Literacy Scale are higher. Overall, reliability values are sufficient for all three scales and for two types of applications.

\section{Conclusion and Discussion}

The results of the current research show that no significant differences were obtained among attitude scores towards teaching profession with regard to common effect of application method and faculty variables. However, significant differences in participant opinions were determined among different application methods (virtual and printed) of Metacognitive Thinking Skills and Information Literacy Scales. In addition, no significant difference was found among opinions towards Metacognitive Thinking Skills and Information Literacy Scales with regard to common effect of application method and faculty variables. Besides, when general scale averages were evaluated, it was seen that virtual survey application score is lower than printed application score of Attitudes towards Teaching Profession Scale and printed survey application scores are lower than virtual application scores of Metacognitive Thinking Skills and Information Literacy Skills Scales.

When an assessment is made in terms of scales, it has been determined that the average scores of printed survey of Attitudes towards Teaching Profession Scale is lower than its virtual version for Sport Sciences and Economics and Administrative Sciences faculties while, average scores of printed survey is higher than its virtual version for Science, Theology and Humanities and Social Sciences faculties. These findings obtained with this scale have not allowed making a realistic assessment. However, when an evaluation is made in terms of the mean scores of Metacognitive Thinking Skills Scale with regard to application method, it is seen that the average scores of the virtual application are higher for all faculties. The lowest difference among the scores regarding both application methods was obtained at the Faculty of Theology. When Information Literacy Scale averages were evaluated, it was determined that the virtual scores are higher in all faculties and the closest values of virtual and printed surveys were obtained for Humanities and Social Sciences Faculty. When all of these findings were evaluated together, a similarity (no significant difference in participant opinions) regarding Attitude towards Teaching Profession Scale, which is a common interest for the whole group in terms of item expressions, and higher points of virtual applications of Cognitive Thinking Skills and Information Literacy scales, which consist of more complex item expressions are attracting attention were seen. Another finding supporting this situation is that the average scores of virtual and printed applications for Humanities and Social Sciences Faculty, which contains departments such as history and literature and which its students are closely related to information literacy skills, are somewhat closer compared to other faculties. Accordingly, it can be said that the applications of virtual and printed surveys may differ significantly from each other and for this reason, may be suspicious in terms of validity of obtained data.

When the findings were examined in terms of faculties and their departments, it will be necessary to explain significant differentiation of scores among applications. According to the impression obtained by the researcher, one reason of difference among the applications is the level of understanding and interpretation. While the students who conducted the printed questionnaires were more deliberate about their own self-efficacy perceptions, the students who conducted the virtual survey application saw themselves more adequate on these topics. In the literature, several studies with similar findings were reported. It is thought that problems arising from screen reading may have been experienced when obtained findings and studies in the literature are evaluated together.

Screen reading is defined as reading either half or the quarter of text on screen as divided pages (Sun, 2009: 317). Aysever (2004) argues that reading electronic texts on computer screen creates a feeling such as entering from one room to another room with more than one door. Güneş (2010) and Altun and Çakmak (2008) are cautious about screen reading for some reasons such as disappearance of one part of a page while reading the other part, foreign characters complicating recognition of the words and nonexistence of initial and last pages thus, complicating perception of text in an ordered format. Whereas, reading is a complex process that has physiological, mental and spiritual aspects such as comprehending, analyzing and evaluating emotions in texts (Çelik, 2006). According to one other researcher (Günay, 2004) reading, a text -regardless of its structure- where words are connected to each other in a meaningful way, is observing connections to discover the meaning derived from coexistence of words and sentences, connecting words to each other to interpret and to find another meaning other than lexical meaning. When all these opinions and findings are evaluated together, it is considered that the virtual survey group may not have understood enough the items they responded to. Perhaps, an experience effect is in question where virtual survey application yielded higher average scores. Filling in the questionnaires in different environments by a group of people who have been exposed more to printed 
questionnaires in their lives has established a ground for this result. By all means, questions, such as whether filling in more virtual questionaries' would have any effect or what effects would a customization create, may be described as critical.

In an experimental study they performed, Tuncer and Bahadir (2014) concluded that the printed-material group was more successful than the screen-reading group in terms of computer lesson achievement scores. In this study, the group (experiment and control) and the common effect of gender were investigated and no statistically significant difference was found. A further research on this research was done by Fleming and Bowden (2009). Fleming and Bowden (2009) compared mail and web-based survey data in terms of some demographic variables, and found no significant difference between the two methods. This result indicates that the findings may change as the environment changes.

Reliability coefficients of Metacognitive Thinking Scale and Attitudes towards Teaching Profession Scale are higher for their printed applications whereas, reliability coefficient is higher for virtual application of Information Literacy Scale. This finding is similar to that of Morris, Woo and Cho (2003). Morris, Woo and Cho (2003) found that reliability of a measurement tool presented in an interactive medium is higher than its paper and pencil form and concluded that the results of non-cognitive tests are similar for both forms of application. On the other hand, in a research Szolnoki and Hoffman (2013) noted that face-to-face surveys gave the best results among the others where they implemented face-to-face, online and telephone survey methods and also that telephone surveys might be a good alternative (but larger sampling is needed) and a lot more corrections or some behavioral variables are needed to be taken into consideration for online surveys. Wiersme (2013) believes that image effects for online surveys can cause mediocre and minor problems on different devices, especially on personal computers and mobile phones. In addition, it has been noted that experiments conducted in one single environment via another means (such as entering the Internet by telephone) did not yield good results, and yet no favorable environments for smartphone-based questionnaires were formed. Nulty (2008) opposes to research that suggests more people can be reached by online surveys (Strachota, Schmidt and Conceicao, 2005; Schmidt, Strachota and Conceição, 2006; Rose and Bogue, 2006) and states that responses to printed questionnaires are higher, but response rates can be increased by various methods.

As the conclusion, based on these research findings, it is not recommended to distribute survey items containing technical information or some complex expressions via smartphones. Relations among the questionnaire content and the department of education confirm this situation. The reason of why the virtual survey group displayed a higher self-efficacy level is a topic that needs to be investigated.

\section{References}

Alshaali, S., \& Varshney, U. (2005) On the usability of mobile commerce. International Journal of Mobile Communications, 3(1), 29-37. https://doi.org/10.1504/IJMC.2005.005872

Altun, A., \& Çakmak, E. (2008). Examining elementary school students' hyper textual reading processes. H. U. Journal of Education, 34, 63-74.

Anameriç, H., \& Rukanc1, F. (2003). E-book technology and its use. Journal of Turkish Librarianship, 17(2), $147-166$. https://doi.org/10.1501/mitos_ymakale_0000005

Annand, D. (2008). Learning efficacy and cost-effectiveness of print versus e-book instructional material in an introductory financial accounting course. Journal of Interactive Online Learning, 7(2), Summer 2008.

Aysever, R. L. (2004). Texts of this era. H.U. Journal of Literature, 21(2), 91-100.

Aytaş, G. (2005). Reading education. Journal of Turkish Educational Sciences, 3(4), 461-470.

Bushanan, E. A., \& Hvizdak, E. E. (2009). Online survey tools: ethical and methodological concerns of human research ethics committees. Journal of Empirical Research on Human Research Ethics, 37-48. https://doi.org/10.1525/jer.2009.4.2.37

Büyüköztürk, Ş., Çokluk, Ö., \& Köklü, N. (2012). Statistics for Social Sciences. Ankara: Pegem Academy Publisghing.

Çelik, C. E. (2006). Comparision of voiced and silent reading with inner reading. Journal of Ziya Gökalp Education Faculty, 7, 18-30.

Çetin, Ş. (2006). Establishment of the profession of teaching attitude scale (The study for validity and confidence). Gazi University Journal of Faculty of Industrial Arts Education, 18, 28-37.

Dyson, M. C. (2004). How physical text layout affects reading from screen. Behaviour and Information Technology, 23(6), 377-393. https://doi.org/10.1080/01449290410001715714

Fleming, C. M., \& Bowden, M. (2009). Web-based surveys as an alternative to traditional mail methods. Journal of Environmental Management, 90(1), 284-292. https://doi.org/10.1016/j.jenvman.2007.09.011 
Gliner, J. A., Morgan, G. A., \& Leech, N. L. (2015). Research methods in practice: An approach integrating design and analysis (Translated by Volkan Bayar, Translated Ed.: Selahattin Turan). Ankara: Nobel Publishing.

Günay, V. D. (2004). Text information. Istanbul: Multilingual Publishing.

Güneş, F. (2007). Turkish Teaching and Mental Configuration. Ankara: Nobel Publishing.

Güneş, F. (2009). Speed Reading and Meaning Configuration. Ankara: Nobel Publishing.

Güneş, F. (2010). Thinking based on screen and screen reading of students. Mustafa Kemal University Journal of Institute of Social Sciences, 7(14), 1-20.

Gunn, H. (2002). Web-based surveys: Changing the survey process. First Monday, 7(12). Retrieved from, https://doi.org/10.5210/fm.v7i12.1014

Karaca, E. (2008). Test and Item Analysis (Ed.: Serdar Erkan and Müfit Gömleksiz). Ankara: Nobel Publishing.

Karasar, N. (2009). Scientific research methods. Ankara: Nobel publishing.

Maden, S. (2012). Screen reading types and opinions of prospective teacher of Turkish language towards screen reading. Journal of Language and Literature Education, 3(1), 1-16.

Mallett, E. (2010). A screen tool for? Findings from an e-book reader pilot. Serials: The Journal for the Serials Community, 23(2). https://doi.org/10.1629/23140

MNE, (2011). Public Relation and Organization Services Module: Active and Fast Reading. http://megep.meb.gov.tr/mte_program_modul/modul_pdf/80OYA0002.pdf

More, N. B., Guy, R. S., \& Elobaid, M. (2007). Reading in a digital age: e-books are students ready for this learning object? Interdisciplinary Journal of Knowledge and Learning Objects, 3, 239-250.

Morris, J. D., Woo, C. M., \& Cho, C. H. (2003). Internet measures of advertising effects: a global issue. Journal of Current Issues and Research in Advertising, 25(1), 25-43. https://doi.org/10.1080/10641734.2003.10505139

Müftüoğlu, G., \& Koç, S. (1998). Listening and Reading Teaching (Ed: Topbaş, S) Turkish Teaching. Eskişehir: Anadolu University Publishing.

Nulty, D. D. (2008). The adequacy of response rates to online and paper surveys: What can be done? Assessment \& Evaluation in Higher Education, 33(3), 301-314. https://doi.org/10.1080/02602930701293231

O'Hara, K., \& Sellen, A. (1997). A comparison of reading paper and on-line documents. CHI '97 Proceedings of the SIGCHI conference on Human factors in computing systems, 335-342. https://doi.org/10.1145/258549.258787

Rosa, R. L, Bressan, G., \& Toledo, G. L. (2012). Analysis of online survey services for marketing research. International Journal of Electronic Commerce Studies, 3(1), 135-144.

Rose, M. M., \& Bogue, B. (2006). A critical assessment of online survey tools. Proceedings of the 2006 WEPAN (Women in Engineering Programs and Advocates Network) Conference, June 11-14, Pennsylvania, USA.

Schmidt,S. W., Strachota, E. W., \& Conceição, S. (2006). The use of online surveys to measure satisfaction in job training and workforce development. http://files.eric.ed.gov/fulltext/ED492858.pdf

Spencer, C. (2006). Research on learners' preferences for reading from a printed text or from a computer screen. Journal of Distance Education, 21(1), 33-50.

Stoop, J., Kreutzer, P., \& Kircz, J. (2013). Reading and learning from screens versus print: a study in changing habits. New Library World, 114(7/8), 284-300. https://doi.org/10.1108/NLW-01-2013-0012

Strachota, E. M., Schmidt, S. W., \& Conceicao, S. (2005). Using online surveys to evaluate distance education programs. 2005 Distance Teaching \& Learning Conference. Madison, WI, University of Wisconsin-Madison.

Szolnoki, G., \& Hoffmann, D. (2013). Online, face-to-face and telephone surveys-comparing different sampling methods in wine consumer research. Wine Economics and Policy, 2(2), 57-66. https://doi.org/10.1016/j.wep.2013.10.001

Timerman, A. (2002). Introduction to the application of web-based surveys. (ERIC Document Reproduction Service No. 474097).

Tuncer, M. (2013). An analysis on the effect of computer self-efficacy over scientific research self-efficacy and information literacy self-efficacy. Educational Research and Reviews, 8(1), 33-40.

Tuncer, M., \& Bahadır, F. (2014). Effect of Screen Reading and Reading from Printed Out Material on Student Success and Permanency in Introduction to Computer Lesson. TOJET: The Turkish Online Journal of Educational 
Technology (July 2014), 13(3), 41-49.

Tuncer, M., \& Kaysi, F. (2011). 'Evaluation of internet cafes in terms of technical infrastructure, services and user propensities (The case of Istanbul and Elazığ cities)', $2^{\text {nd }}$ International Conference on New Trends in Education and Their Implications, 27-29 April 2011, Antalya-Turkey.

Tuncer, M., \& Kaysi, F. (2013). The development of the metacognitive thinking skills scale. International Journal of Learning \& Development, 3(2),70-76. https://doi.org/10.5296/ijld.v3i2.3449

Tuncer, M., Yılmaz, Ö., \& Tan, Ç. (2011). 'Evaluation of internet as a source of information according to the students of the department of the computer and instructional technologies', 5th International Computer \& Instructional Technologies Symposium, 22-24 September 2011 Firat University, Elazığ-Turkey.

Vernon, R. (2006). Teaching notes paper or pixels? An inquiry into how students adapt to online text books. Journal of Social Work Education, 42(2), 417-427. https://doi.org/10.5175/JSWE.2006.200404104

Weeks, L. (2002). E-books not exactly flying off the shelves: Most readers stick to paper despite technology's hype. The Washington Post.

Wiersma, W. (2013). The validity of surveys: Online and offline. http://papers.wybowiersma.net/abstracts/Wiersma,Wybo,The_validity_of_surveys_online_and_offline.pdf

Wilson, R. (2003). Ebook readers in higher education. Educational Technology \& Society, 6(4), 8-17.

Yıldırım, G., Karaman, S., Çelik, E., \& Esgice, M. (2011). A literature review: e-book readers' using experience. $5^{\text {th }}$ International Computer \& Instructional Technologies Symposium, 22-24 September, Elazığ.

\section{Copyrights}

Copyright for this article is retained by the author(s), with first publication rights granted to the journal.

This is an open-access article distributed under the terms and conditions of the Creative Commons Attribution license which permits unrestricted use, distribution, and reproduction in any medium, provided the original work is properly cited. 